\title{
Money Announcements, The Demand for Bank Reserves, and the Behavior of the Federal Funds Rate within the Statement Week
}

\section{Citation}

Campbell, John Y. 1987. Money announcements, the demand for bank reserves, and the behavior of the federal funds rate within the statement week. Journal of Money, Credit and Banking 19 , no. 1: 56-67.

\section{Published Version}

http://dx.doi.org/10.2307/1992245

\section{Permanent link}

http://nrs.harvard.edu/urn-3:HUL.InstRepos:3220231

\section{Terms of Use}

This article was downloaded from Harvard University's DASH repository, and is made available under the terms and conditions applicable to Other Posted Material, as set forth at http:// nrs.harvard.edu/urn-3:HUL.InstRepos:dash.current.terms-of-use\#LAA

\section{Share Your Story}

The Harvard community has made this article openly available.

Please share how this access benefits you. Submit a story.

\section{Accessibility}


NBER WORKING PAPER SERIES

MONEY ANNOUNCEMENTS, THE DEMAND

FOR BANK RESERVES AND THE BEHAVIOR

OF THE FEDERAL FUNDS RATE

WITHIN THE STATEMENT WEEK

John Y. Campbe 11

Working Paper No. 1806

NATIONAL BUREAU OF ECONOMIC RESEARCH

1050 Massachusetts Avenue

Cambridge, MA 02138

January 1986

I am grateful to Bill Gavin, Robert Litterman, Carl Walsh and two anonymous referees for helpful discussions and comments on an earlier version of this paper. I am responsible for any remaining errors. The research reported here is part of the NBER's research program in Financial Markets and Monetary Economics. Any opinions expressed are those of the author and not those of the National Bureau of Economic Research. 
NBER Working Paper \#1806

January 1986

Money Announcements, the Demand for Bank Reserves

and the Behavior of the Federal Funds Rate

Within the Statement Week

\section{ABSTRACT}

The effect of money stock announcements on the Federal funds rate has been attributed informally to the information conveyed by the announcements about aggregate reserve demand. This "Aggregate Information Hypothesis" explains the effect without reference to Federal Reserve intervention in the funds market. In this paper I provide a formal model of the Aggregate Information Hypothesis under lagged reserve accounting. The model relies on imperfect information in the funds market, and on imperfect bank arbitrage of reserve demand between days of the week. Some stylized facts are presented about funds rate behavior in the period 1980-1983.

John Y. Campbell Department of Economics Princeton University Dickinson Hall

Princeton, NJ 08544 


\section{Introduction}

This paper documents two puzzling features of Federal funds rate behavior under lagged reserve accounting in the early $1980^{\prime} \mathrm{s}$, and presents a stylized model of the funds market which explains these features.

The first noteworthy fact which is analyzed is that day-to-day changes in the rate within the statement week may be significantly positive or negative on average across weeks, and are serially correlated. This fact is puzzling, as pointed out by Shiller, Campbell and Schoenholtz [1983], because banks must hold reserves to meet an average requirement over the statement week. The funds rate is the daily price of holding reserves, and one would expect banks to adjust their reserve holdings across days to eliminate any predictable changes in the funds rate through the week. That is, one would expect the funds rate to follow a martingale within the statement week. ${ }^{1}$

Secondly, there has been a significant effect of Friday M1 money stock announcements on the Federal funds rate. When the money stock, which is announced with a two week lag, is announced to have been surprisingly large, the funds rate has tended to rise.

The announcement effect on longer term interest rates may be explained as the result of expected policy reactions (when $M 1$ is high, the Fed is expected to tighten and raise real rates), or an expected change in policy (a positive M1 surprise indicates a higher long-run money growth rate and higher expected inflation). ${ }^{2}$ It is harder to explain the announcement ef-

1 This argument is unaffected by the change from lagged to contemporaneous reserve accounting in early 1984.

2 Roley and Walsh [1985] present a model of these effects. 
fect on the funds rate in this manner. The inflation story seems implausible for an overnight rate, while the tightening story requires that after a high money announcement the Federal Reserve reduces nonborrowed reserves at the end of a statement week relative to the beginning of the week. It is hard to see why the Federal Reserve should behave in this way; after all, it has some foreknowledge of the announcement, so that it could tighten early in the week. This would reduce the interest rate response to the announcement, something which the Federal Reserve has publicly said would be desirable.

Shiller, Campbell and Schoenholtz [1983] proposed an alternative explanation for the money announcement effect on the Federal funds rate. They pointed out that under lagged reserve accounting, the announcement of M1 from two weeks ago is an announcement of current aggregate demand for bank reserves. ${ }^{3}$ Before the announcement, banks know their own reserve requirements but not the reserve demand of other banks. If banks collectively underestimate aggregate reserve demand, but know the position of the supply curve for reserves, then the money announcement will raise the expected end-of-week funds rate. By the arbitrage argument given above, the funds rate will rise immediately.

Nichols and Small [1985] have criticized this explanation, which they call the "Aggregate Information Hypothesis" (AIH), on the following ground. If the supply curve for reserves is known, as postulated by the AIH, then the Federal funds rate in the first part of the week reveals the demand for reserves in that part of the week. Nichols and Small argue that this is

3 In fact M1 contains public currency holdings and thus is not equivalent to reservable deposits. For simplicity this distinction will be ignored in what follows. 
tantamount to revealing aggregate reserve demand for the week as a whole, so that the money stock announcement conveys no new information under the AIH.

In this paper I argue to the contrary, that a money announcement may convey information even if there is no uncertainty about the position of the supply curve for reserves. This is possible because banks may be uncertain about the timing of other banks' reserve demands within the statement week; thus the funds rate in the first part of the week reveals "ear$1 y "$ reserve demand but does not necessarily reveal "late" reserve demand. The formal model which illustrates this point also generates predictable changes in the funds rate through the week. Such deviations from martingale behavior are a necessary (but not sufficient) condition for the Aggregate Information Hypothesis as modelled here. ${ }^{4}$

The model of this paper should not be interpreted as a complete description of all the factors which affect the Federal funds market. Rather, it is a highly stylized representation of one aspect of Federal funds rate determination. Relevant empirical results on Federal funds rate behavior in 1980-83 are briefly presented in Section 2 of the paper. Section 3 develops the formal model for lagged reserve accounting, and section 4 concludes .

4 Walsh [1983] presented a formal model of intraweek bank reserve demand with some similarities to the one worked out here. The most important difference is that in Walsh's model banks are uncertain about the supply of reserves within the week, so that the model is not a pure illustration of the Aggregate Information Hypothesis. Also Walsh focuses on aggregate uncertainty of banks, rather than the individual bank's inference from private and public information which is studied in this paper. 


\section{Empirical Evidence, 1980-83}

In this section I briefly present some evidence that the Federal funds rate has not followed a martingale within the week, and that it was affected by money stock surprises in the lagged reserve accounting period. Table 1 summarizes funds rate behavior in a 4-year period from the 8 th week of 1980 (when the money announcement was moved from Thursday to Friday) to the last week of 1983. Lagged reserve accounting was in effect throughout this period, and the statement week ran from Thursday to Wednesday. Statement weeks in which the funds market was closed for a holiday on any day are omitted from the sample, leaving 170 observations. The sample is broken in half at the end of 1981; the two subsamples have 83 and 87 observations respectively. Money stock surprises are measured as the difference between announced Ml and the median forecast from a survey taken by Money Market Services, Inc., on the previous Tuesday. Funds rates, obtained from the Federal Reserve Board and the Federal Reserve Bank of Philadelphia, are measured as "effective" rates, that is as daily trade-weighted averages.

Some statistical problems arise in testing the martingale hypothesis using this measure of the Federal funds rate. If the funds rate takes a single value each day (perhaps with noise specific to each transaction during the day), and changes systematically overnight, then the daily average data corresponds to point-in-time data and changes in daily averages should be unpredictable under the martingale hypothesis. If on the other hand the funds rate opens each day at the previous day's closing price, but evolves continuously during the day, then under the martingale hypothesis the daily average data have the properties described by Working [1960]. ${ }^{5}$ Changes in

5 Strictly speaking Working's results apply to random walks with constant 
daily averages should have first-order serial correlation of 0.25 and higher-order serial correlations of zero under the martingale hypothesis.

Rather than rely on one or the other interpretation of the funds rate data, I show that the martingale hypothesis for the funds rate can be rejected under either interpretation. The first four rows of Table 1 present summary statistics for daily changes in the funds rate within the statement week. Under either interpretation of the daily average data, if the funds rate were a martingale mean daily changes would all be insignificantly different from zero. However in the full sample and each subsample two out of four mean daily changes are significantly different from zero at the $5 \%$ leve1. There is a predominance of negative signs, indicating that the funds rate tends to fall through the statement week.

The last four rows of Table 1 summarize some regressions which describe the dynamics of funds rate behavior. In rows 5 to 7 I regress the change in the funds rate on the previous day's change. Standard errors in parentheses are the heteroskedasticity-consistent standard errors proposed by MacKinnon and White [1984]. These have desirable finite-sample as we11 as asymptotic properties. They are uniformly larger than the unadjusted standard errors, and thus represent a conservative evaluation of the significance of the coefficients.

In row 5 the previous day's funds rate change is shown to have a highly significant positive effect on the funds rate change from Tuesday to Wednesday, in the full sample and both subsamples. The lagged change is almost as significant in row 6 , with the exception of the second subsample.

innovation variance. The variances of daily average funds rate changes alter systematically through the week, as described below. This complication is ignored in what follows. 
In row 7 , however, the change from Friday to Monday is shown to have an insignificant correlation with the change from Thursday to Friday. The regression of row 5 rejects the martingale hypothesis at the $5 \%$ level for either interpretation of the daily average data; the regression of row 6 rejects it only if the daily averages are equivalent to point-in-time data. ${ }^{6}$ These results are consistent with those reported by Cornell [1983] for a sample period roughly equivalent to the first subsample here. ${ }^{7}$

Row 8 shows that there is a significant contemporaneous reaction of the funds rate to money announcement surprises, in the full sample and both subsamples. ${ }^{8}$ The daily averaging problem does not affect the money announcement regressions, since the announcement occurs between trading days.

- Results which are not reported, for lack of space, show that there is significant second-order serial correlation of funds rate changes. This is inconsistent with the martingale hypothesis, even if the daily average data suffer from the Working problem.

7 Cornell stressed that there is negative serial correlation between the change on the last day of one statement week, and the change on the first day of the next week. This is not inconsistent with the martingale hypothesis.

8 Regressions not reported found no evidence of a lagged reaction to money surprises. 
3. A Rational Expectations Model of Reserve Demand

Under Lagged Reserve Accounting

In this section I develop a model of bank reserve demand which helps to explain the observed features of funds rate behavior under lagged reserve accounting. ${ }^{9}$ In particular, the model generates predictable differences between the funds rate early and late in the statement week, and it allows the existence of a money announcement effect on the funds rate without assuming that the Fed reacts to announcements within the week.

The formal model treats the Federal funds rate as the cost to a bank of holding its reserves on a particular day of the week. The justification for this treatment is that the funds rate is the cost to an individual bank of increasing reserves at one margin, or the benefit to it of reducing reserves at that margin. There are of course other margins where banks can increase or reduce reserves; for example, they can borrow at the discount window or sell securities. However at the optimum costs are equated at all margins and the model uses the funds rate as an indicator of these costs. Furthermore the funds rate is assumed to be the same for all banks; it would be easy to generalize the model to allow for a constant difference in funds rates across banks.

Under lagged reserve accounting, each bank $j$ knows its overall reserve requirement for the statement week, $R_{j}$, at the beginning of the week. The bank must choose its reserve holdings for the first day of the week knowing $R_{j}$ and the first-day federal funds rate, $r_{1}$, but without knowing the funds rate that will prevail later in the week.

- Details of calculations are in an Appendix available from the author. 
For simplicity I divide the statement week into only two "days".10 Then the bank must choose first-and second-day reserve holdings, $R_{1 j}$ and $R_{2 j}$, subject to $R_{1 j}+R_{2 j}=R_{j}$. If there were no costs associated with adjusting reserves between the first and second days, the bank would simply hold reserves on the day with the lowest (expected) federal funds rate. This behavior on the part of all banks would eliminate any predictable change in the rate from the first to the second day.

However there are predictable changes in the funds rate, and one can imagine a number of reasons why banks find it costly to adjust the timing of reserve holdings within the week. For example, there may be an inventory motive for reserve holdings, to finance stochastic inflows to and outflows from a bank's reserve account. Rather than model this explicitly, I simply introduce a first-day reserve "target", $T_{1 j}$, together with a quadratic cost of deviation from the target. Bank $j$ chooses $R_{1 j}$ to minimize the cost function

(1) Min $C=r_{1} R_{1 j}+E_{j}\left[r_{2}\right]\left(R_{j}-R_{1 j}\right)+(\alpha / 2)\left(R_{1 j}-T_{1 j}\right)^{2}$

The first-order condition for this problem is

(2) $R_{1 j}=T_{1 j}+(1 / \alpha)\left[E_{j}\left[r_{2}\right]-r_{1}\right]$

It is apparent from (2) that $\alpha>0$ is necessary if expected differences between $r_{2}$ and $r_{1}$ are not to generate unbounded shifts in reserve demand.

10 A money announcement is then modelled as a change from one equilibrium to another in the first day, rather than as a real-time event occurring between two days of the week. Walsh [1983] used a three-day model of the statement week. This enabled him to model money announcements in real time, at the cost of greater complexity in intertemporal aspects of his mode 1 . 
The first-order condition (2) contains the bank's expectation of the second-day federal funds rate, $E_{j}\left[r_{2}\right]$. In order to model this expectation as rational, we must state explicitly the information problem of the bank.

On the demand side, the bank knows $R_{j}$ and $T_{1 j}$. Suppose that

(3) $R_{j}=a+u+\varepsilon_{j}$

Here $a$ is a constant, $u$ is an aggregate shock affecting all banks (a shock to the quantity of money two weeks earlier), and $\varepsilon_{j}$ is an idiosyncratic shock affecting only bank $j . \quad u$ and $\varepsilon_{j}$ are normally distributed with zero means and variances $V_{u}$ and $V_{\varepsilon}$ respectively. If there are $J$ banks in total, I assume $(1 / J) \sum \varepsilon_{j}=0$. Then average reserve demand across banks is $R=$ $(1 / J) \Sigma R_{j}=a+u$.

Suppose also that

(4) $T_{1 j}=b_{j}+v+\eta_{j}$

The first-day reserve target $T_{1 j}$ is some constant fraction $b$ of the bank $j$ total reserve requirement, plus an aggregate shock $\mathrm{v}$ and an idiosyncratic shock $\eta_{j} \cdot v$ and $\eta_{j}$ are normally distributed with zero means and variances $v_{v}$ and $V_{\eta}$ respectively. $u, v, \varepsilon_{j}$ and $\eta_{j}$ are all independent. I assume $(1 / J) \Sigma \eta_{j}=0$. Then the average first-day reserve target across banks is $\mathrm{T}_{1}=\mathrm{bR}+\mathrm{v}$.

On the supply side, the Federal Reserve supplies reserves to the banking system as a whole according to some rule which I assume is constant across the two days of the statement week, and known to individual banks at the beginning of the week. ${ }^{11}$ For simplicity, assume this rule is linear in

11 Note that the supply function for reserves includes borrowed reserves; thus the implicit penalty for discount window borrowing is incorporated 
the Federal funds rate:

$$
\text { (5) } \mathrm{R}_{\mathrm{i}}=\mathrm{c}+\mathrm{dr} \mathrm{r}_{\mathrm{i}} \quad \mathrm{i}=1,2
$$

where $R_{i}=(1 / J) \sum R_{i j}$. This supply schedule is consistent with the analysis of Hetzel [1982], so long as the funds rate exceeds the discount rate. A more complicated supply rule, perhaps of the intertemporal variety proposed by Goodfriend [1983], could be analyzed without much change in the results of the model, so long as the rule is known to banks and does not vary through the week.

At the beginning of the week, each bank knows $c$ and $d$ and observes $r_{1}$, so each bank knows $R_{1}$. The information problem for the bank is to infer whether first-day reserve demand is high because of an aggregate shock $u$ to overall demand $R$, or because of an aggregate shock $v$ to the first-day component of this demand. Bank j's knowledge of $R_{j}$ and $T_{1 j}$ does not reveal the values of $u$ and $v$ because of the idiosyncratic shocks $\varepsilon_{j}$ and $\eta_{j}$. Formally, we can write $E_{j}\left[r_{2}\right]=E\left[r_{2} \mid I_{j}\right]$, where $I_{j}=\left\{R_{j}, T_{1 j}, r_{1}\right\}$.

Equations (2) through (5), together with the rational expectations condition, the definitions of aggregates and the reserve constraint $R_{1 j}+$ $R_{2 j}=R_{j}$, make up a complete model of the determination of reserve demand within the statement week. The model is solved by applying the method of undetermined coefficients.

First note that the first-order condition (3), when aggregated across banks, implies

(6) $c+d r_{1}=b(a+u)+v+(1 / \alpha)\left[E\left[r_{2}\right]-r_{1}\right]$

into this supply function. 
where $E\left[r_{2}\right]=(1 / J) \quad \sum \quad E_{j}\left[r_{2}\right]$ is the average of individual banks ' expectations of $r_{2}$. Equality of supply and demand for reserves on the second day of -the week implies that

(7) $c+d r_{2}=R_{2}=R-R_{1}=a+u-\left(c+d r_{1}\right)$.

Now postulate that interest rates on the first and second days of the week are linear in the underlying shocks to the model:

(8) $r_{1}=\phi_{1} u+\phi_{2} v+\phi_{3}$

where $\phi_{1}, \phi_{2}$ and $\phi_{3}$ are coefficients which are as yet undetermined. From (7) and (8),

(9) $\mathrm{r}_{2}=\left(1 / \mathrm{d}-\phi_{1}\right) \mathrm{u}-\phi_{2} \mathrm{v}+((\mathrm{a}-2 \mathrm{c}) / \mathrm{d}-\phi 3)$.

Next postulate that bank j's expectation is linear in its information:

$$
E_{j}\left[r_{2}\right]=\pi_{1} R_{j}+\pi_{2} T_{1 j}+\pi_{3} r_{1}+\pi_{4}
$$

where $\pi_{1}, \pi_{2}, \pi_{3}$ and $\pi_{4}$ are also undetermined coefficients. The structure of the model allows straightforward solution for the $\phi$ coefficients if we know the $\pi$ coefficients, and vice versa.

The simplest case, which I solve first, is the perfect information case: $E_{j}\left[r_{2}\right]=r_{2}$ for all $j$. Banks have full information if either $V_{\varepsilon}$ or $V_{\eta}$ is zero, for then either $u$ or $v$ is revealed through equation (3) or (4), and the remaining aggregate shock is revealed through observation of $r_{1}$.

The model as stated is degenerate if $\alpha$ is zero, because the first-order condition divides zero by zero. However under one further assumption it can be shown that banks have perfect information in this case. The as- 
sumption is that when banks have zero $\alpha$, and expect no change in the funds rate, they choose their first-day reserves as a deterministic linear function of the variables they observe, where the function is common across banks. We may write $R_{1 j}=\psi_{1} R_{j}+\psi_{2} T_{1 j}+\psi_{3} r_{1}$. This equation may be aggregated across banks, and since $R_{1}=c+d r_{1}$, one can substitute out $r_{1}$ to get an equation which describes first-period reserve demand as a function of the underlying shocks $u$ and $v$. Taking expectations, the equation must also hold for $E[u]$ and $E[v]$.

Since no bank expects a change in the funds rate, we have $E_{j}\left[r_{2}\right]=$ $E\left[r_{2}\right]=r_{1}$. It follows that reserve demand is expected to be equal on the two days, so half of total demand for the week is expected on the first day: $R_{1}=(a+E[u]) / 2$. The only values of the $\psi$ parameters which satisfy this condition have $\psi_{2}=0$ and $R_{1}=(a+u) / 2$. It follows that in the equilibrium with $\alpha$ equal to zero, banks are fully informed and finance half their reserve needs each day.

A similar argument can be used to show that for any value of $\alpha$, if each bank knows $E[u]$ each bank is perfectly informed. Confusion arises in this model when banks are uncertain about the aggregate of other banks' expectations.

The perfect information case is solved by substituting (8) and (9) into (6). One obtains an equation which must hold for arbitrary u and $v$. The values of the $\phi$ coefficients which permit this are $\phi_{1}=\phi_{1} *=(1+\mathrm{b} \alpha \mathrm{d}) / \mathrm{d}(2+\alpha \mathrm{d}), \quad \phi_{2}=\phi_{2} *=\alpha \mathrm{d} / \mathrm{d}(2+\alpha \mathrm{d}), \quad$ and $\phi_{3}=\phi_{3} *=[a(1+b \alpha d)-c(2+\alpha d)] / d(2+\alpha d)$.

These results are fairly intuitive. A shock to overall reserve demand, $u$, raises both $r_{1}$ and $r_{2}$ : it raises them equally if $b=1 / 2$, for in 
this case banks wish to distribute their additional reserve demand equally across days of the week, or if $\alpha=0$. In these cases $u$ does not affect the difference between $r_{1}$ and $r_{2}$. A shock to the first-day reserve target, $v$, raises $r_{1}$ and lowers $r_{2}$ so that the average of the two rates is unaffected. $v$ has no effect on the funds rates if $\alpha=0$, that is if banks are infinitely willing to arbitrage across days of the week. When $b=1 / 2$ or $\alpha=0$, the constant terms simplify to $[a-2 c] / 2 d$ for each equation. When $b>1 / 2$ for nonzero $\alpha, r_{1}$ tends to be greater than $r_{2}$ on average across weeks, as observed in the 1980-83 period.

The imperfect information case is more complex. The first step in solving it is to find the values of the $\phi$ coefficients which are consistent with given values of the $\pi$ coefficients. Aggregating equation (10) across banks, and substituting it and equation (8) into equation (6), one finds $\phi_{1}=b \phi_{2}+\pi_{1} /\left(1+\alpha d-\pi_{3}\right)$ and $\phi_{2}=\left(\alpha+\pi_{2}\right) /\left(1+\alpha d-\pi_{3}\right)$. The value of $\phi_{3}$ is the same as $\phi_{3} *$ above.

The next step is to obtain the $\pi$ coefficients as functions of the $\phi$ coefficients. Since $r_{2}, R_{j}, T_{1 j}$ and $r_{1}$ are multivariate normal, one can apply the formula for the forecast of a normal variable $y$ conditional on a vector of normal variables $x$. Lengthy calculations yield $\pi_{1}=\left[\phi_{2} \mathrm{~V}_{\mathrm{u}} \mathrm{V}_{\mathrm{v}}\left(\mathrm{b} \phi_{1} \mathrm{~V}_{\varepsilon}+\phi_{2} \mathrm{~V}_{\eta}\right)\right] / \Delta \mathrm{d}, \quad \pi_{2}=\left[-\phi_{1} \phi_{2} \mathrm{~V}_{\mathrm{u}} \mathrm{V}_{\mathrm{v}} \mathrm{V}_{\varepsilon}\right] / \Delta \mathrm{d}, \quad$ and $\pi_{3}=\left[\phi_{1} V_{u} V_{\varepsilon}\left(V_{v}+V_{\eta}\right)\right] / \Delta d-1$,

where $\Delta=\phi_{1}^{2} V_{u} V_{\varepsilon}\left(V_{v}+V_{\eta}\right)+\phi_{2}^{2} V_{v} V_{\eta}\left(V_{u}+V_{\varepsilon}\right)$

$\pi_{4}$ is determined so that the average value of $E\left[r_{2}\right]$ across weeks is the same as the average value of $\mathrm{r}_{2}$ under full information.

Substituting out for the $\pi$ coefficients, we obtain a pair of quadratic equations in $\phi_{1}$ and $\phi_{2}$ : 
(11)

$$
\begin{aligned}
& \Gamma \phi_{1}=b \Gamma \phi_{2}+\phi_{2} V_{u} V_{v}\left[b \phi_{1} V_{\varepsilon}+\phi_{2} V_{\eta}\right] \\
& \Gamma \phi_{2}=\alpha d \Delta-\phi_{1} \phi_{2} V_{u} V_{v} V_{\varepsilon}
\end{aligned}
$$

where $\Gamma=(2+\alpha d) d \Delta-\phi_{1} V_{u} V_{\varepsilon}\left(V_{v}+V_{\eta}\right)$

In general these equations may have multiple solutions. Rather than attempting to analyze the model solution in the general case, I here examine small deviations from the full information case. If $V_{\varepsilon}$ or $V_{\eta}$ is zero, $\phi_{1}$ and $\phi_{2}$ are equal to $\phi_{1} *$ and $\phi_{2} *$. What is the effect of a small increase in $V_{\varepsilon}$ from zero? This can be answered by evaluating the derivatives of (11) with respect to $\phi_{1}, \phi_{2}$ and $V_{\varepsilon}$, at the full information point. Further lengthy calculations yield the following result:

$$
\begin{aligned}
& \partial \phi_{1} / \partial \mathrm{V}_{\varepsilon}=-1 / \mathrm{d}(2+\alpha \mathrm{d}) \mathrm{V}_{\mathrm{u}}=-\phi_{2} * / \alpha d \mathrm{~V}_{\mathrm{u}} \\
& \partial \phi_{2} / \partial \mathrm{V}_{\varepsilon}=(1+\mathrm{b} \alpha \mathrm{d}) /\left(\mathrm{d}(2+\alpha \mathrm{d}) \alpha \mathrm{dV} \mathrm{V}_{\mathrm{v}}\right)=\phi_{1} * / \alpha d V_{\mathrm{v}}
\end{aligned}
$$

It must be emphasized that these expressions are correct only at the full information point. The variance of $\eta$ does not appear in (12), but the underlying calculations require that $V_{\eta} \neq 0$. Economically, if $V_{\eta}=0$ then banks have full information whatever the variance of $\varepsilon$, and $\partial \phi_{2} / \partial V_{\varepsilon}=$ $\partial \phi_{1} / \partial V_{\varepsilon}=0$.

The importance of equations (12) is that they show that $\phi_{1}$ falls as the equilibrium becomes noisy, while $\phi_{2}$ increases. Intuitively, when the equilibrium is noisy banks confuse $u$ and $v$ shocks. A $u$ shock to overall reserve demand is thought by each bank to be partly a $\mathrm{v}$ shock to the firstday reserve target, which will lower the funds rate on the second day of the week. Banks respond by shifting reserve demand to the second day, lowering the first-day funds rate; $\phi_{1}$ is lower than under full information. 
Similarly a $v$ shock, raising the first-day reserve target for all banks, is thought by each bank to be partly a u shock to overall reserve demand throughout the statement week. Accordingly banks do not fully anticipate the decline in reserve demand and the funds rate that will in fact occur on the second day of the week, and they shift less of their reserve demand towards the second day. This keeps the funds rate high on the first day, so $\phi_{2}$ is higher than under full information.

Confusion of this sort can explain why there is a money announcement effect on the federal funds rate, without any need to appeal to intra-week shifts in reserve supply. We have noted that under lagged reserve accounting, a money announcement is an announcement of current aggregate reserve demand $R=a+u$. Accordingly it shifts the funds market from the noisy equilibrium to the fully informed equilibrium, without changing any real conditions in the market.

One can derive some propositions about the money announcement effect even without the imperfect information model solution (12). First, from the aggregated first-order condition (6), the change in the first-period funds rate resulting from the announcement obeys $\partial r_{1} / \partial A=$ $(1 /(1+\alpha d)) \partial E\left[r_{2}\right] / \partial A$. The money announcement does not change aggregate reserve demand for the week as a whole, so it can affect the first-day funds rate only by changing the expected second-day funds rate in the same direction.

Next, we note from equation (7) that $\partial r_{1} / \partial A=-\partial r_{2} / \partial A$, again because the money announcement does not change aggregate reserve demand for the week. Thus if the move to the informed equilibrium raises the first-day funds rate, it raises the expected second-day rate and lowers the actual 
second-day rate; in the informed equilibrium, these two variables are equa 1.

If we take expectations of (7), we find that $\partial E\left[\mathrm{r}_{2}\right] / \partial A=$ $(1 / d) \partial E[u] / \partial A$. The expected funds rate rises because banks increase their estimates of aggregate reserve demand for the week. A positive surprise in the money announcement (one which increases $E[u]$ ) raises the expected second-day funds rate and thus the actual first-day funds rate. This is the money announcement effect observed in the 1980-83 period.

From equation (8), we also know that $\phi_{1} \partial E[u] / \partial A=-\phi_{2} \partial E[v] / \partial A$. Banks observed the first-day funds rate before the announcement; if they increase their estimates of $u$ they must decrease their estimates of $v$ to remain consistent with observed $r_{1}$.

The contribution of the imperfect information model solution is to show for what values of $u$ and $v$ a positive money surprise (and thus an increase in first-day rates) occurs. For an infinitesimally noisy equilibrium, we can measure the money announcement effect on the first-day rate by evaluating at the parameter values $\phi_{1} *$ and $\phi_{2} *$ the derivatives of $\phi_{1}$ and $\phi_{2}$ with respect to the variance of $\varepsilon$ (or equivalently $\eta$ ), the noise in the system .

For such an infinitesimally noisy equilibrium, the effect of the announcement, A, on the first-period funds rate is

$$
\partial \mathrm{r}_{1} / \partial \mathrm{A}=-\left(\partial \phi_{1} / \partial \mathrm{V}_{\varepsilon}\right) \mathrm{u}-\left(\partial \phi_{2} / \partial \mathrm{V}_{\varepsilon}\right) \mathrm{v}=\phi_{2} * \mathrm{u} / \alpha \mathrm{dV} \mathrm{u}_{\mathrm{u}}-\phi_{1} * \mathrm{v} / \alpha \mathrm{dV} \mathrm{V}_{\mathrm{v}}
$$

Since $\phi_{1} *$ and $\phi_{2} *$ are both positive, a positive money surprise occurs when there is a high value of $u$ and a low value of $v$; the low v "disguises" the high $u$ by offsetting its effect on the first-day funds rate. 
The model of this section has relied heavily on the institutional framework of lagged reserve accounting. Since early 1984, this reserve accounting system has been superseded by contemporaneous reserve accounting. It would be straightforward to alter the model to describe a money announcement effect on the funds rate under the new regime. Under contemporaneous reserve accounting, banks do not know their required reserves for certain until the end of the statement week; but each bank has some private information early in the week about its own deposits and thus about its reserve requirement. The announcement of the money stock from two weeks earlier is no longer an announcement of this week's aggregate required reserves, but if there is persistence through time in the money stock the announcement does convey useful information about this magnitude. Thus the necessary elements for the Aggregate Information Hypothesis are still present under contemporaneous reserve accounting. 


\section{Conclusion}

In this paper I have argued that random shifts in banks' desired timing of reserve holdings can explain some otherwise puzzling features of Federal funds rate behavior within the statement week. I have developed a model for the lagged reserve accounting regime, in which such shifts generate predictable changes in the funds rate from one part of the week to another. They also create confusion so that the funds rate does not perfectly aggregate private information, and an announcement of the money stock moves the market to a more informed equilibrium. In this model, a money announcement may alter the Federal funds rate even when there is no uncertainty about Federal Reserve supply behavior within the statement week. 
TABLE 1

DAILY FUNDS RATE BEHAVIOR

Row Variable

$1980: 8-83: 52 \quad 1980: 8-81: 52 \quad 1982: 1-83: 52$

Mean change

(Standard error of estimate)

(Standard deviation of change)

\begin{tabular}{|c|c|c|c|c|}
\hline 1 & $F_{W E D}-F_{\text {TUES }}$ & $\begin{array}{l}-0.047 \\
(0.066) \\
(0.861)\end{array}$ & $\begin{array}{l}-0.206 \% \\
(0.121) \\
(1.109)\end{array}$ & $\begin{array}{c}0.105 * \\
(0.051) \\
(0.479)\end{array}$ \\
\hline 2 & $F_{\text {TUES }}{ }^{-F_{M O N}}$ & $\begin{array}{l}-0.111 * \\
(0.038) \\
(0.499)\end{array}$ & $\begin{array}{l}-0.180 * \\
(0.071) \\
(0.644)\end{array}$ & $\begin{array}{l}-0.045 \\
(0.031) \\
(0.286)\end{array}$ \\
\hline 3 & $\mathrm{~F}_{\mathrm{MON}}-\mathrm{F}_{\mathrm{FRI}}$ & $\begin{array}{c}0.020 \\
(0.043) \\
(0.563)\end{array}$ & $\begin{array}{c}0.027 \\
(0.074) \\
(0.677)\end{array}$ & $\begin{array}{c}0.013 \\
(0.046) \\
(0.426)\end{array}$ \\
\hline 4 & $\mathrm{~F}_{\text {FRI }}-\mathrm{F}_{\text {THURS }}$ & $\begin{array}{l}-0.109 \div \div: \\
(0.032) \\
(0.423)\end{array}$ & $\begin{array}{l}-0.101 \\
(0.057) \\
(0.519)\end{array}$ & $\begin{array}{l}-0.116 * \\
(0.033) \\
(0.304)\end{array}$ \\
\hline
\end{tabular}

Coefficient on previous day's change (Standard error)

(Regression R-Squared)

\begin{tabular}{|c|c|c|c|c|}
\hline 5 & $F_{\text {WED }}{ }^{-F_{\text {TUES }}}$ & $\begin{array}{l}0.628 \div \div \\
(0.174) \\
(0.132)\end{array}$ & $\begin{array}{l}0.628 * * \\
(0.215) \\
(0.133)\end{array}$ & $\begin{array}{l}0.448 * \\
(0.217) \\
(0.071)\end{array}$ \\
\hline & $F_{\text {TUES }}-F_{\text {MON }}$ & $\begin{array}{l}0.387 \div \div \\
(0.100) \\
(0.191)\end{array}$ & $\begin{array}{l}0.524 * * \\
(0.109) \\
(0.304)\end{array}$ & $\begin{array}{c}0.063 \\
(0.125) \\
(0.009)\end{array}$ \\
\hline & $F_{M O N}-F_{F R I}$ & $\begin{array}{l}0.052 \\
(0.120) \\
(0.002)\end{array}$ & $\begin{array}{c}0.089 \\
(0.136) \\
(0.005)\end{array}$ & $\begin{array}{l}-0.049 \\
(0.264) \\
(0.001)\end{array}$ \\
\hline & & \multicolumn{3}{|c|}{$\begin{array}{c}\text { Coefficient on money surprise } \\
\text { (Standard error) } \\
\text { (Regression R-Squared) }\end{array}$} \\
\hline 3 & $F_{M O N}-F_{F R I}$ & $\begin{array}{l}0.065 \% \\
(0.020) \\
(0.065)\end{array}$ & $\begin{array}{l}0.072 \div \\
(0.034) \\
(0.065)\end{array}$ & $\begin{array}{l}0.055 \% \\
(0.019) \\
(0.068)\end{array}$ \\
\hline
\end{tabular}

Note: $*=$ significant at the $5 \%$ level, $* *$ significant at the $1 \% 1$ eve 1 . 
Corne11, Bradford, "Monetary Policy and the Daily Behavior of Interest Rates", Journal of Economics and Business Vo1. 35 pp. 189-203, 1983.

Goodfriend, Marvin A., "Discount Window Borrowing, Monetary Policy and the Post-October 6, 1979 Federal Reserve Operating Procedure", Journal of Monetary Economics Vol. 12 pp. 343-356, September 1983.

Hetzel, Robert L., "The October 1979 Regime of Monetary Control and the Behavior of the Money Stock in 1980", Journal of Money, Credit and Banking Vol. 14 pp. 234-251, May 1982.

MacKinnon, James G. and Halbert White, "Some Heteroskedasticity Consistent Covariance Matrix Estimators with Improved Finite Sample Properties", unpublished paper, Queen's University, December 1984.

Nichols, Donald A. and David H. Small, "The Effect of Money Announcements in the Federal Funds Market", unpublished paper, April 1985.

Roley, V. Vance and Carl E. Walsh, "Monetary Policy Regimes, Expected Inflation, and the Response of Interest Rates to Money Announcements", Quarterly Journal of Economics Supplement pp. 1011-1039, 1985.

Shiller, Robert J., John Y. Campbell and Kermit L. Schoenholtz, "Forward Rates and Future Policy: Interpreting the Term Structure of Interest Rates", Brookings Papers on Economic Activity 1983:1 pp. 173-217, 1983.

Walsh, Carl E., "The Effects of Alternative Operating Procedures on Economic and Financial Relationships", in Monetary Policy Issues of the $1980^{\prime} \mathrm{s}$, Federal Reserve Bank of Kansas City, 1983.

Working, Holbrook, "Note on the Correlation of First Differences of Averages in a Random Chain", Econometrica Vol. 28 No. 4 pp. 916-918, 1960. 